\title{
Author Correction: HMGB2 is a novel adipogenic factor that regulates ectopic fat infiltration in skeletal muscles
}

\author{
Deokcheol Lee, Noboru Taniguchi, Katsuaki Sato, Narantsog Choijookhuu, \\ Yoshitaka Hishikawa, Hiroaki Kataoka $\oplus^{D}$, Hidetaka Morinaga, Martin Lotz \& Etsuo Chosa
}

Correction to: Scientific Reports https://doi.org/10.1038/s41598-018-28023-7, published online 25 June 2018

The original version of this Article contained an error in Affiliation 6, which was incorrectly given as 'Department of Internal Medicine and Bioregulatory Science, Graduate School of Medical Sciences, 3-1-1 Maidashi, Higashi, Fukuoka, 812-8582, Japan'. The correct affiliation is listed below:

Department of Internal Medicine and Bioregulatory Science, Graduate School of Medical Sciences, Kyushu University, 3-1-1 Maidashi, Higashi, Fukuoka, 812-8582, Japan.

Additionally, in the Supplementary Information file originally published with this Article, Affiliation 2 was incorrectly given as 'Department of Medical Science, Tokyo Medical University, 6-1-1 Shinjuku, Shinjuku, Tokyo 1608402, Japan.' The correct affiliation is listed below:

Institute of Medical Science, Tokyo Medical University, 6-1-1 Shinjuku, Shinjuku-ku, Tokyo, 160-8402, Japan

These errors have now been corrected in the HTML and PDF versions of the article, alongside the Supplementary information file.

(c) (i) Open Access This article is licensed under a Creative Commons Attribution 4.0 International License, which permits use, sharing, adaptation, distribution and reproduction in any medium or format, as long as you give appropriate credit to the original author(s) and the source, provide a link to the Creative Commons license, and indicate if changes were made. The images or other third party material in this article are included in the article's Creative Commons license, unless indicated otherwise in a credit line to the material. If material is not included in the article's Creative Commons license and your intended use is not permitted by statutory regulation or exceeds the permitted use, you will need to obtain permission directly from the copyright holder. To view a copy of this license, visit http://creativecommons.org/licenses/by/4.0/.

(C) The Author(s) 2020 